\title{
PENGATURAN FOLKLOR SECARA SUI GENERIS DALAM UNDANG-UNDANG TERSENDIRI ${ }^{1}$
}

\author{
Yusna Melianti, Julia Ivanna, Reh Bungana Beru Perangin-angin \\ Fakultas Ilmu Sosial Universitas Negeri Medan \\ Jl. Willem Iskandar Pasal V Medan 20221 \\ Email: yusmelianti@gmail.com, ivannajulia@yahoo.com,rei.angin@gmail.com
}

\begin{abstract}
This research aimed to analyze the setting offolklore in Indonesia and other countries; and analyze why folklore needs to be regulated by sui generis system. This research is empirical normative. In Indonesia folklore is regulated under copyright law. Folklore regulation in national legal systems of each country is different. Folklore regulation under the scope of the copyright law is not appropriate. Folklore should be regulated separately by a special law governing folklore.
\end{abstract}

Keywords : Folklore; Copyright; Sui Generis.

\begin{abstract}
Abstrak
Penelitian ini bertujuan untuk menganalisis pengaturan folklor di Indonesia dan negara lain; dan menganalisis mengapa folklor perlu diatur secara sui generis. Penelitian ini merupakan penelitian normatif empiris. Indonesia mengatur folklor dalam undang-undang hak cipta. Pengaturan folklor dalam sistem hukum nasional masing-masing negara tidak sama. Pengaturan folklor di bawah lingkup undang-undang hak cipta tidak tepat. Folklor harus diatur secara tersendiri dalam undangundang khusus yang mengatur folklor.
\end{abstract}

Kata Kunci : Folklor; Hak Cipta; Sui Generis.

\section{A. Pendahuluan}

1. Latar Belakang Permasalahan

Indonesia merupakan negara yang terdiri dari beraneka ragam etnik, suku bangsa, dan agama. ${ }^{2}$ Setiap suku bangsa memiliki seni tradisional, budaya dan adat istiadat yang telah diturunkan dari satu generasi ke generasi selanjutnya. Seni tradisional, budaya, dan adat istiadat merupakan bagian dari folklor. Melindungi folklor merupakan suatu hal yang sangat penting, sebab apabila folklor punah maka akan punah juga identitas dari masyarakat pemiliknya.

Pada awalnya penggunaan folklor hanya terbatas pada masyarakat pemilik folklor. Akan tetapi, seiring berkembangnya pengetahuan, teknologi dan transportasi, penggunaan folklor berkembang tidak hanya dalam masyarakat pemiliknya tetapi juga masyarakat lain di luar masyarakat pemilik. Folklor dalam bentuk aslinya maupun reproduksinya menjadi salah satu objek komersial dalam konteks industri maupun perdagangan. ${ }^{3}$ Ada kekhawatiran hal tersebut dapat mendorong terjadinya penyalahgunaan

\footnotetext{
1. Artikel ini merupakan hasil penelitian dari Penelitian Fundamental yang berjudul Pengaturan Folklor Secara Sui Generis Dalam Undang-Undang Tersendiri. Tim Peneliti terdiri dari : Ketua : Dra. Yusna Melianti, MH., Anggota (1) Julia Ivanna, S.Sos., M.AP., dan Anggota (2) Dr. Reh Bungana Beru Perangin-angin, SH., M.Hum. Semua peneliti merupakan dosen Fakultas Ilmu Sosial Universitas Negeri Medan.

2. "Indonesia Miliki 1.128 Suku Bangsa", tersedia di website http://www.jpnn.com/index.php?id=57455\&mib $=$ berita.detail, diakses pada tanggal 26 Januari 2014 .

3. Brian A. Prastyo, "Mencari Format Kebijakan Hukum Yang Sesuai Untuk Perlindungan Folklor di Indonesia", tersedia di website http://www.lkht.net/index.php, diakses pada tanggal 7 Maret 2011.
} 
(misappropriation), perusakan nilai kebudayaan serta menyebabkan terjadinya eksploitasi yang tidak layak oleh orang asing.

Kekhawatiran tersebut ternyata benarbenar terjadi. Beberapa folklor Indonesia telah disalahgunakan dan eksploitasi secara tidak layak oleh pihak asing. Salah satu contohnya adalah tindakan warga negara Inggris Christopher Harrison melalui perusahaannya Harrison \&Gil yang mengklaim hak cipta ukiran Jepara. ${ }^{5}$ Kasus klaim lainnya adalah klaim Malaysia terhadap Reog Ponorogo, lagu daerah Rasa Sayange, Tari Pendet, motif Batik khas Indonesia, ${ }^{6}$ Tari Tor-tor, dan alat musik Gondang Sambilan (Sembilan Gendang).

Klaim atas folklor Indonesia yang dilakukan pihak asing akhir-akhir ini dianggap sebagai akibat masih kurangnya perlindungan terhadap folklor oleh pemerintah Indonesia. ${ }^{7}$ Kurangnya perlindungan terhadap folklor tersebut karena undang-undang yang mengatur tentang folklor tidak memadai dalam memberikan perlindungan terhadap folklor. Selain itu, tidak ada peraturan pemerintah yang mengatur tentang folklor. Saat ini pengaturan folklor di Indonesia dimasukkan ke dalam Undang-Undang No. 28 Tahun 2014 Tentang Hak Cipta selanjutnya disebut dengan UUHC 2014. UUHC 2014 menyebut folklor dengan istilah Ekspresi Budaya Tradisional (EBT). Berdasarkan latar belakang ini maka permasalahan yang akan dikaji meliputi bagaimana pengaturan folklor di Indonesia, dan negara lain dan mengapa folklor perlu diatur secara suigeneris.

\section{Metode Penelitian}

Penelitian mengenai Pengaturan Folklor Secara Sui Generis Dalam Undang-Undang Tersendiri merupakan penelitian normatif empiris. Penelitian normatif-empiris ini bersifat evaluatif. Metode berpikir evaluatif dimaksudkan untuk melihat dan menemukan hukum seperti apa yang lebih baik/seharusnya. Adapun jenis data yang digunakan dalam penelitian ini adalah data sekunder dan data primer. Pengumpulan data primer dilakukan melalui wawancara, observasi, dan pencatatan. Observasi dan wawancara dilakukan dengan pihak-pihak yang terkait dengan perlindungan folklor di Wae Rebo, Desa Satar Lenda, Kecamatan Satarmese Barat, Manggarai, Pulau Flores, Nusa Tenggara Timur. Pengumpulan data sekunder dilakukan dengan melakukan penelusuran terhadap bahan hukum primer, bahan hukum sekunder, dan bahan hukum tersier. Data yang diperoleh baik data sekunder maupun data primer dianalisis secara kualitatif yaitu data yang diperoleh dari kepustakaan dan dibandingkan dengan data yang ada dalam praktik di lapangan untuk kemudian ditarik kesimpulan sebagai jawaban atas permasalahan yang diteliti. Penarikan kesimpulan dilakukan dengan menggunakan metode deduktif dan induktif. Metode deduktif atau metode penalaran merupakan metode untuk menarik kesimpulan dari hal-hal umum ke hal-hal khusus, sedang metode induktif adalah kebalikan dari metode deduktif yaitu menarik kesimpulan dari hal-hal yang khusus ke halhal yang bersifat umum. ${ }^{8}$

\section{Kerangka Teori}

Folklor dalam istilah-istilah resmi, disebut dengan beberapa istilah seperti expression of folklore, cultural expressions, traditional cultural expression atau ekspresi budaya tradisional. WIPO Performances and Phonograms Treaty (WIPO) dan United Nations Educational, Scientific and Cultural Organization (UNESCO) menyebut istilah folklor dengan sebutan folklore, traditional cultural expressions (TCEs) dan expressions of folklore. Meskipun banyak perbedaan istilah, akan tetapi secara internasional

\footnotetext{
4. Ibid.

5. Tempo.news com, “Jepara Fasilitasi Pengajuan Hak Paten”, tersedia di website, diakses pada tanggal 26 Januari 2014.

6. Antara News.com, "Saatnya Indonesia Melawan Klaim Budaya Oleh Asing," tersedia di website http://portal.antaranews.com/print/152069/saatnya-indonesia-melawan-klaim-budaya-oleh-asing, diakses pada tanggal 25 Juli 2011.

7. Anton Sumantri, "Perlu Perlindungan Hukum Bagi Budaya Tradisional Indonesia", tersedia di website http://www.unpad.ac.id/archives/13603, diakses pada tanggal 15 Mei 2011.

8. Soerjono Soekanto, 1990, Pengantar Penelitian Hukum, Cetakan Ketiga, Jakarta, UI Press, hlm. 75.
} 
sejumlah ilmuan, akademisi, organisasi, pemerintah ${ }^{9}$ dan Tunis Model Law menggunakan istilah folklor. Oleh karena itu, dalam tulisan ini digunakan istilah folklor.

Folklor merupakan milik bersama (komunal) masyarakat pemiliknya. Tidak ada individu yang memiliki folklor itu secara pribadi karena masyarakatlah yang membuat folklor tersebut ada. ${ }^{11}$ Folklor merupakan karya-karya tradisional yang tumbuh dan berkembang dalam kehidupan masyarakat asli sebagai kekayaan intelektual milik masyarakat asli. ${ }^{12}$ Istilah masyarakat asli merupakan terjemahan harfiah dari "indigenous peoples". Indigenous peoples adalah istilah yang disepakati dalam hukum internasional untuk menyebut suatu entitas masyarakat yang mempunyai karakteristik tersendiri karena latar belakang sejarah, ekonomi, sosial dan budayanya. Beberapa folklor mempunyai nilai ekonomi tinggi baik dalam perdagangan nasional maupun internasional. Folklor juga memberi kontribusi ekonomi dalam bidang pariwisata. Selain itu, folklor mempunyai nilai ekonomi dalam kaitannya dengan industri budaya. Perlindungan yang memadai dan tepat atas folklor dapat memberikan kontribusi kepada kesejahteraan kepada masyarakat pemilik folklor.

Pengaturan folklor mengalami perubahan dalam UUHC 2014, akan tetapi perubahan tersebut tidak memberikan pengaruh yang berarti dalam perlindungan folklor. Hal ini disebabkan karena folklor tidak sesuai dilindungi dengan undangundang hak cipta (UUHC). Ketidaksesuaian tersebut antara lain karena sifat folklor yang bertentangan dengan hak cipta. Salah satu contohnya adalah hak cipta merupakan kepemilikan perorangan (individual) sedangkan folklor merupakan milik bersama (komunal). ${ }^{13}$ Selain itu, folklor sering tidak diketahui siapa penciptanya dan tidak orisinil (asli) karena diwariskan secara turun temurun. ${ }^{14}$ Adapun persyaratan dalam perlindungan hak cipta adalah harus jelas siapa yang menjadi pencipta ${ }^{15}$ dan ciptaan harus bersifat orisinil. ${ }^{16}$ Dengan demikian, UUHC kurang sesuai untuk melindungi folklor. ${ }^{17}$ Folklor seharusnya dilindungi secara tersendiri dalam undang-undang yang khusus mengatur folklor.

\section{B. Hasil dan Pembahasan}

\section{Pengaturan Folklor di Indonesia dan} Negara Lain

\section{a. Pengaturan Folklor di Indonesia}

Indonesia mengatur folklor sebagai bagian dari Hak Cipta. Pengaturan folklor sebagai bagian dari hak cipta sudah dimasukkan ke dalam UUHC pertama Indonesia. Pada tahun 1982 Indonesia menetapkan Undang-Undang No. 6 Tahun

9. Wend B. Wendland, "Intellectual Property, Traditional Knowledge And Folklore: Wipo's Exploratory Program", IIC 2002, 33(4), 485-504, International Review of Intellectual Property and Competition Law, 2002, pp. 485-504, hlm. 492.

10. Christoph Antons, "What is "Traditional Cultural Expression?", International Definitions And Their Application in Developing Asia”, W.I.P.O.J. 2009, 1(1), 103-116, WIPO Journal, 2009, pp. 103-116. hlm 109.

11.Weerawit Weeraworawit, "Formulating An International Legal Protection For Genetic Resources, Traditional Knowledge And Folklore: Challenges For The Intellectual Propertysystem", 11 Cardozo J. Int'1 \& Comp. L. 769, Cardozo Journal of International and Comparative Law, Summer 2003, pp. 769-783, hlm. 773.

12. Zainul Daulay, 2011, Pengetahuan Tradisional : Konsep, Dasar Hukum, Dan Praktiknya, Jakarta, PT. Raja Grafindo Persada, hlm. 39-40.

13. Jake Philips, "Australia's Heritage Protection Act : An Alternative to Copyright in the Struggle to Protect Communal Interests in Authored Works of Folklore", Pacific Rim and Policy Journal, 18 Pac. Rim L. \& Pol'y J. 547, August 2009, pp. 547-573, hlm. 549 .

14.Stephanie Spangler, "When Indigenous Communities Go Digital : Protecting Traditional Cultural Expressions Through Integration of IP and Customary Law", 27 Cardozo Arts \& Ent.L.J.709., Cardozo Arts and Entertainment Law Journal, 2010, pp. 709-736, hlm. 711.

15. Susanna Frederick Fischer "Dick Whittington And Creativity: From Trade To Folklore, From Folklore To Trade", Symposium "The Power of Stories: Intersections of Law, Literature, and Culture The Dick Whittington Story: Its Influences \& Its Impacts, 12 Tex. Wesleyan L. Rev. 5, Texas Wesleyan Law Review, Fall 2005, pp. 5-66, hlm. 20.

16. Molly Torsen, "Intellectual Property And Traditional Cultural Expressions: A Synopsis Of Current Issues", 3 Intercultural Hum. Rts. L. Rev. 199, Intercultural Human Rights Law Review, 2008, pp. 199-214, hlm. 203.

17. Silke von Lewinski, "The Protection Of Folklore", 11 Cardozo J. Int'l \& Comp. L. 747, Cardozo Journal of International and Comparative Law, Summer 2003, pp. 747-768, hlm. 757. 
1982 tentang Hak Cipta yang merupakan UUHC pertama Indonesia. Saat ini pengaturan tentang folklor di Indonesia diatur dalam UUHC 2014. Sama seperti UUHC sebelumnya, hak cipta atas folklor menurut UUHC 2014 dipegang oleh Negara (Pasal 38 ayat (1) UUHC 2014). Pasal 60 Ayat (1) UUHC 2014 menjelaskan hak cipta atas folklor berlaku tanpa batas waktu (abadi). Adapun yang dimaksud dengan folklor di dalam Penjelasan Pasal 38 ayat (1) UUHC 2014 mencakup salah satu atau kombinasi bentuk ekspresi sebagai berikut :

1) verbal tekstual, baik lisan maupun tulisan, yang berbentuk prosa maupun puisi, dalam berbagai tema dan kandungan isi pesan, yang dapat berupa karya sastra ataupun narasi informatif;

2) musik, mencakup antara lain, vokal, instrumental, atau kombinasinya;

3) gerak, mencakup antara lain, tarian;

4) teater, mencakup antara lain, pertunjukan wayang dan sandiwara rakyat;

5) seni rupa, baik dalam bentuk dua dimensi maupun tiga dimensi yang terbuat dari berbagai macam bahan seperti kulit, kayu, bambu, logam, batu, keramik, kertas, tekstil, dan lain-lain atau kombinasinya; dan

6) upacara adat.

Sebelum berlakunya UUHC 2014, folklor diatur dalam UUHC 2002. Di dalam Penjelasan Pasal 10 ayat (2) UUHC 2002 dinyatakan:

Folklor dimaksudkan sebagai sekumpulan ciptaan tradisional, baik yang dibuat oleh kelompok maupun perorangan dalam masyarakat, yang menunjukkan identitas sosial dan budayanya berdasarkan standar dan nilai-nilai yang diucapkan atau diikuti secara turun temurun, termasuk:

1. cerita rakyat, puisi rakyat;

2. lagu-lagu rakyat dan musik instrumen tradisional;

3. tari-tarian rakyat, permainan tradisional;

4. hasil seni antara lain berupa: lukisan, gambar, ukiran-ukiran, pahatan, mosaik, perhiasan, kerajinan tangan, pakaian, instrumen musik dan tenun tradisional.

Ada beberapa perubahan perlindungan folklor dalam UUHC 2014. Lingkup karya yang dilindungi sebagai folklor merupakan salah satu yang berubah. Jika dalam UUHC 2002, upacara adat tidak dilindungi sebagai folklor maka dalam UUHC 2014 upacara adat memperoleh perlindungan sebagai folklor. Ini merupakan suatu hal yang sangat baik, karena Indonesia sangat kaya dengan upacaraupacara adat yang bernilai sakral yang hidup dan dilestarikan oleh masyarakat-masyarakat asli Indonesia. Hanya saja, ada beberapa perubahan yang merupakan kemunduran dalam perlindungan folklor Indonesia. Tenun tradisional yang semula disebutkan secara khusus dalam UUHC 2002 sebagai folklor yang dilindungi, saat ini tidak lagi disebut dalam pengertian folklor dalam UUHC 2014.

Selain tenun tradisional, bentuk arsitektur (architectural forms) merupakan salah satu kekayaan budaya tradisional Indonesia yang tidak ternilai harganya. Bentuk arsitektur ini diwujudkan dalam bangunan-bangunan tradisional atau rumahrumah adat masyarakat asli di Indonesia. Indonesia patut bangga dengan kekayaan arsitektur tradisionalnya yang berbeda dan unggul dari negara-negara lain. ${ }^{18}$ Bentuk arsitektur (rumah adat) tidak dilindungi sebagai folklor di Indonesia. Tanpa memasukan arsitektur rumah adat ke dalam folklor nasional yang dilindungi maka akan sangat merugikan bagi negara dan kepada masyarakat asli pemilik rumah adat. Saat ini, beberapa rumah adat di Indonesia sudah hampir mengalami kepunahan karena kurang perhatian dan kepedulian dari pemerintah dan masyarakat asli pemilik rumah adat. Salah satu rumah adat yang berada dalam kondisi rentan dan hampir punah adalah rumah adat Mbaru Niang warisan kebudayaan Manggarai. Pada tahun 2009, rumah adat Mbaru Niang hanya tinggal 4 (empat) dari 7 (tujuh) buah rumah yang diwariskan secara

18. Shilta Finella, “Arsitektur Tradisional Di Indonesia", Shilta Finella, "Arsitektur Tradisional Di Indonesia”, tersedia di website Http://www.scribd.com/doc/53070439/Arsitektur-Tradisional-Indonesia, diakses pada tanggal 10 Oktober 2015. 
turun temurun. Setelah dikonservasi saat ini Mbaru Niang telah kembali berjumlah 7 (tujuh) buah. Mbaru Niang merupakan rumah tradisional di Wae Rebo, Desa Satar Lenda, Kecamatan Satarmese Barat, Manggarai, Pulau Flores, Nusa Tenggara Timur. Mbaru Niang meraih Award of Excellence, anugerah tertinggi dalam UNESCO Asia-Pacific Awards for Cultural Heritage Conservation $2012 .^{19}$

Mbaru Niang masuk dalam nominasi internasional Aga Khan Award for Architecture (AKAA). Preservasi Mbaru Niang terpilih sebagai salah satu kandidat AKAA tahun 2013. Perlindungan rumah tradisional Mbaru Niang, berhasil masuk nominasi 20 besar dalam AKAA. Pelestarian Mbaru Niang dimulai oleh arsitek Yori Antar. Proses pelaksanaan preservasi dilakukan dan dipimpin oleh masyarakat setempat. ${ }^{20}$ Saat ini Mbaru Niang masih dihuni oleh masyarakat asli. Setelah Mbaru Niang meraih Award of Excellence, Mbaru Niang ramai dikunjungi oleh jurnalis, antropolog, arsitek, peneliti, dan wisatawan baik dari dalam maupun luar negeri. Rumah adat Mbaru Niang yang berjumlah 7 (tujuh) buah tersebut kini sudah mendunia. Salah satu dari rumah adat tersebut saat ini difungsikan sebagai penginapan bagi pengunjung yang datang dan menginap di Wae Rebo.

Kehidupan masyarakat Wae Rebo pun secara sosial mulai berubah. Masyarakat yang semula seolah terisolasi dari dunia luar karena berada di atas perbukitan kini sudah terbiasa berinteraksi dengan masyarakat pendatang. Secara ekonomi, masyarakat asli Wae Rebo juga mengalami perubahan. Masyarakat asli
Wae Rebo mengelola pendapatan yang diperoleh dari pengunjung. Sejak Wae Rebo ramai dikunjungi, sebagian masyarakat Wae Rebo aktif menjadi pemandu bagi pengunjung yang datang ke Wae Rebo. Perubahan lainnya adalah dalam bidang pendidikan. Saat ini sudah terdapat sekolah Pendidikan Anak Usia Dini dan perpustakaan kecil di Wae Rebo.

Baik dalam UUHC 2002 maupun UUHC 2014 "architectural forms" (bentuk arsitektur) tidak dilindungi sebagai folklor. Padahal Model Provisions for National Laws on the Protection of Expressions of Folklore Againts Illict Exploitation and Other Prejudicial Actions (Model Provisions) ${ }^{21}$ dan WIPO IC-GRTKF, The Protection Of Traditional Cultural Expressions/Expressions Of Folklore: Revised Objectives And Principles, Seventeenth Session Geneva, December 6 to 10, 2010 mencantumkan bahwa bentuk arsitektur merupakan bagian dari folklor yang dilindungi.

\section{b. Pengaturan Folklor di Negara Lain}

Pengaturan folklor dalam sistem hukum nasional masing-masing negara tidak sama. Ada negara yang mengatur perlindungan folklor di bawah UU HKI seperti Sri Lanka. Beberapa negara mengaturnya sebagai bagian dari UUHC, seperti Indonesia, Australia, Barbados, Iran, Nigeria, Kongo, dan Ghana. Di sisi lain, beberapa negara mengatur folklor secara sui generis ${ }^{23}$ dalam UU yang khusus mengatur folklor seperti Kroasia, Filipina, Vietnam, Azerbaijan, dan Panama.
1) Sri Lanka
Perlindungan folklor di Sri Lanka didasarkan pada Undang-Undang Kekayaan

19. Pemerintah Daerah Provinsi Nusa Tenggara, "Mbaru niang raih penghargaan Unesco", tersedia di website http://indonesia.go.id/in/pemerintah-daerah/provinsi-nusa-tenggara-timur/2162-kebudayaan/1 1488-mbaru-niangraih-penghargaan-unesco, diakses pada tanggal 17 Mei 2015.

20. Kompas.com, "Mbaru niang dapat penghargaan tertinggi", tersedia di website http://nasional.kompas.com/read/2012/08/30/0421412/mbaru.niang.dapat.penghargaan.tertinggi, diakses pada tanggal 15 Mei 2015.

21. Meghan Ruesch, "Creating Culture: Protection Of Traditional Cultural Expressions And Folklore And The Impact On Creation And Innovation In The Marketplace Of Ideas”, 35 Syracuse J. Int'1 L. \& Com. 369, Syracuse Journal of International Law and Commerce, Spring 2008, pp. 369-398., hlm. 371 .

22. Jake Philips., Loc. cit., lihat juga Paul Kuruk, "Protecting Folklore Under Modern Intellectual Property Regimes: A Reappraisal Of The Tensions Between Individual And Communal Rights In Africa And The United States," 48 Am. U. L. Rev. 769, American University Law Review., April 1999, pp. 769-849.

23.WIPO Intergovernmental Committee on Intellectual Property and Genetic Resources, Traditional Knowledge and Folklore, Glossary Of Key Terms Related To Intellectual Property And Genetic Resources, Traditional Knowledge And Traditional Cultural Expressions, Twenty-Third Session Geneva, February 4 to 8, 2013. 
Intelektual No. 36 Tahun 2003 selanjutnya disebut UU Sri Lanka. Menurut Pasal 24 (1) UU Sri Lanka, folklor harus dilindungi dari reproduksi, pertunjukan ke publik, penyiaran, distribusi dengan kabel atau cara lain, serta adaptasi, penerjemahan, dan transformasi lain ketika folklor tersebut digunakan baik untuk tujuan komersial maupun di luar konteks tradisional atau adat mereka. Izin untuk menggunakan folklor bergantung pada pembayaran biaya yang ditetapkan dan disetujui oleh pejabat yang berwenang yang ditentukan oleh menteri. Uang yang terkumpul akan digunakan untuk pengembangan budaya. ${ }^{24}$

Pengecualian dari Pasal 24 (1) UndangUndang Sri Lanka, yaitu terdapat dalam Pasal 24 (2) Undang-Undang Sri Lanka yang menentukan bahwa izin dan pembayaran biaya tidak diberlakukan untuk penggunaan folklor seperti penggunaan pribadi, melaporkan kejadian terkini, pengajaran, kritik, komentar, dan penelitian. Selanjutnya, perlindungan folklor seharusnya tidak mencegah masyarakatnya dari penggunaan, penukaran, dan transmisi antara mereka sendiri atas folklor dari warisan budaya mereka dengan cara tradisional dan adat serta mengembangkan folklor tersebut dengan reaksi terus menerus dan imitasi. ${ }^{25}$

\section{2) Panama}

Pada tahun 2000, Panama mensahkan Undang-Undang No. 20 yang mengakui sistem kekayaan intelektual masyarakat asli secara sui generis yang pertama di dunia. Undang-Undang No. 20 mengamanatkan bahwa pemerintah Panama mempromosikan dan menyebarluaskan budaya masyarakat asli melalui pendidikan wajib publik ${ }^{26}$ Perlindungan di dalam Undang-Undang No. 20 tidak bersifat otomatis. Perlindungan atas hak komunal hanya dapat diperoleh melalui pendaftaran. Pendaftaran hanya dapat diminta oleh Kongres Umum atau Otoritas Tradisional Masyarakat Asli dan hanya untuk hak-hak komunal. UU No. 20 memberikan masyarakat asli hak eksklusif untuk menggunakan dan mengkomersialkan kreasi mereka. Di antaranya, mereka memiliki hak untuk melarang orang lain mengklaim kepemilikan seni mereka, hak untuk melarang orang lain dari menyatakan seni bukan milik masyarakat asli sebagai milik masyarakat asli, hak untuk mengecualikan orang lain dari membuat salinan meniru seni mereka, dan hak untuk melarang semua industri atau mekanik (yaitu tidak dengan tangan) reproduksi seni dan pengetahuan tradisional mereka. $^{27}$

\section{3) Australia}

Australia mengatur folklor dalam Undang-undang Hak Cipta. Pada tahun 2000, perubahan Undang-undang Hak Cipta menambahkan sarana yang efektif pada Undang-undang Hak Cipta untuk melengkapi penghargaan untuk karya seorang pencipta dan memberikan perlindungan terhadap penggunaan yang menghina karya tersebut. Penggunaan menghina termasuk penggunaan atau pengubahan karya yang merugikan kehormatan atau reputasi pencipta. Meskipun UUHC mengatur kekayaan intelektual dari pencipta karya seni, undang-undang tersebut gagal memberikan perlindungan yang memadai bagi folklor yang melibatkan kepentingan masyarakat asli. Kegagalan ini disebabkan sebagian besar UUHC fokus atas perlindungan individu pencipta untuk jangka waktu yang terbatas. Fokus yang bertentangan dengan kepemilikan komunal dan abadi karya tersebut di bawah hukum adat masyarakat asli. ${ }^{28}$

Menurut UUHC Australia, sebelum hak cipta diberikan kepada pencipta, ciptaan harus memenuhi tiga persyaratan sebagai berikut :
a) harus asli
b) harus dalam bentuk materi (misalnya, ditulis atau direkam dalam bentuk nyata); dan
c) harus memiliki pencipta yang dapat diidentifikasi. $^{29}$

\footnotetext{
24. Indunil Abeyesekere, "The Protection Of Expressions OfFolklore In Sri Lanka," IIC 2007, 38(2), 183-203, 25 International Review of Intellectual Property and Competition Law, 2007,pp. 183-203., hlm. 184.

25. Ibid, hlm. 185.

Irma De Obaldia, "Western Intellectual Property And Indigenous Cultures: The Case Of The Panamanian Indigenous

26.Intellectual Property Law", 23 B.U.Int'l L.J. 337, Boston University International Law Journal, Fall 2005, pp. 337

27 394., hlm. 365.

27. Ibid, hlm. 368 .

28. Jake Philips, Op.cit., hlm. 549.
} 
Melalui persyaratan yang ditetapkan oleh UUHC Australia maka undang-undang tersebut tidak cukup melindungi folklor masyarakat Aborigin sebagai masyarakat asli dari Australia. Hal ini disebabkan, UUHC Australia hanya melindungi karya asli yang diketahui penciptanya dan harus dalam bentuk materi. Adapun folklor sudah digunakan selama beberapa generasi sehingga tidak asli karena telah berevolusi dan juga sudah tidak diketahui siapa penciptanya. Selanjutnya, syarat materi yang ditetapkan oleh UUHC Australia sangat sulit untuk dipenuhi oleh folklor karena banyak folklor yang diturunkan secara lisan dari satu generasi ke generasi selanjutnya.

\section{Folklor Perlu Diatur Secara Sui Generis}

Pengaturan folklor di bawah lingkup undang-undang hak cipta adalah tidak tepat. Ada beberapa sifat dasar folklor yang sangat bertentangan dengan hak cipta. Perbedaan yang paling mendasar antara folklor dengan hak cipta yaitu :

a. Hak cipta merupakan kepemilikan individual sedangkan folklor merupakan kepemilikan komunal karena merupakan identitas bersama masyarakat pemiliknya.

b. Folklor sering tidak diketahui siapa penciptanya karena diturunkan dari satu generasi ke generasi selanjutnya, sedangkan hak cipta harus jelas siapa yang menjadi pencipta.

c. Hak cipta harus bersifat orisinil (asli) sedangkan folklor tidak orisinil karena telah digunakan oleh beberapa generasi.

d. Hak cipta harus bersifat tetap (berwujud) sedangkan folklor banyak yang tidak bersifat berwujud karena ditularkan atau diceritakan secara lisan.

e. Perlindungan folklor bersifat abadi sedangkan perlindungan hak cipta mempunyai batas waktu.

Jadi dengan demikian, pengaturan folklor harus terpisah dari pengaturan hak cipta. Folklor harus diatur secara sui generis dalam undang-undang khusus yang mengatur folklor. Pada tahun 2007, Indonesia telah berusaha mengatur folklor dalam undangundang tersendiri dengan membuat Rancangan Undang-Undang Tentang
Perlindungan dan Pemanfaatan Kekayaan Intelektual Pengetahuan Tradisional dan Ekspresi Budaya Tradisional (selanjutnya disebut RUU EBT). Di dalam RUU tersebut folklor disebut dengan Ekspresi Budaya Tradisional (EBT), yaitu karya intelektual dalam bidang seni, termasuk ekspresi sastra yang mengandung unsur karakteristik warisan tradisional yang dihasilkan, dikembangkan, dan dipelihara oleh komunitas atau masyarakat tertentu. Pasal 1 angka 2 RUU Ekspresi Budaya Tradisional, 4 September 2009.

RUU EBT telah mencakup hal-hal yang sangat mendasar dalam perlindungan folklor. Namun, pengaturan folklor dalam RUU tersebut belum memadai karena masih terdapat beberapa kekurangan. Kekurangan tersebut antara lain : definisi dan ruang lingkup folklor kurang luas, perlindungan folklor tidak abadi, dan menekankan pada pengaturan tentang cara dan syarat pemanfaatan folklor tapi tidak menjelaskan syarat-syarat perlindungannya.

Atas dasar hal itu, sebelum RUU EBT disahkan sebagai undang-undang, ada baiknya disempurnakan dan ditambahkan beberapa hal dalam RUU tersebut, agar undang-undang tersebut nantinya benarbenar memberikan perlindungan yang memadai bagi folklor masyarakat asli. Adapun beberapa hal yang harus disempurnakan dan ditambahkan dalam RUU tersebut adalah :

\section{a. Definisi Folklor}

Hal pertama yang harus disempurnakan adalah mengenai definisi folklor di dalam RUU EBT. Definisi folklor di dalam RUU EBT disebutkan dalam Pasal 1 angka (2). Pasal 1 angka (2) menyatakan : "ekspresi budaya tradisional adalah karya intelektual dalam bidang seni yang mengandung unsur karakteristik warisan tradisional yang dihasilkan, dikembangkan, dan dipelihara oleh komunitas atau masyarakat tertentu." Selanjutnya, ekspresi budaya tradisional yang dilindungi menurut RUU EBT diatur di dalam Pasal 2 ayat (3). Berdasarkan Pasal 2 ayat (3), ekspresi budaya tradisional yang dilindungi mencakup salah satu atau kombinasi bentuk ekspresi berikut ini: 
a) verbal tekstual, baik lisan maupun tulisan, yang berbentuk prosa maupun puisi, dalam berbagai tema dan kandungan isi pesan, yang dapat berupa karya susastra ataupun narasi informatif;

b) musik, mencakup antara lain: vokal, instrumental atau kombinasinya;

c) gerak, mencakup antara lain: tarian, beladiri, dan permainan;

d) teater, mencakup antara lain: pertunjukan wayang dan sandiwara rakyat;

e) seni rupa, baik dalam bentuk dua dimensi maupun tiga dimensi yang terbuat dari berbagai macam bahan seperti kulit, kayu, bambu, logam, batu, keramik, kertas, tekstil, dan lain-lain atau kombinasinya; dan

f) upacara adat, yang juga mencakup pembuatan alat dan bahan serta penyajiannya.

Selanjutnya, baik RUU EBT maupun UUHC 2014 juga tidak mencantumkan bentuk arsitektur sebagai folklor yang dilindungi. Ini juga merupakan suatu keputusan yang kurang bijaksana. Hal ini disebabkan, Indonesia memiliki berbagai macam arsitektur tradisional yang sangat luar biasa dan mengagumkan yang telah ada sejak sejak berabad-abad yang lalu. Arsitektur tradisional tersebut diwujudkan dalam bentuk rumah adat maupun bangunan-bangunan tradisional lainnya. Seiring dengan perkembangan zaman dan teknologi, sebagian rumah adat dan bangunan tradisional telah mengalami kepunahan. Maka dari itu, sangat penting untuk melindungi arsitektur tradisional sebagai folklor yang dilindungi.

b. Jangka Waktu Perlindungan Folklor

RUU EBT memberikan jangka waktu perlindungan yang terbatas atas folklor, yaitu sepanjang folklor tersebut masih dipelihara oleh pemiliknya. Hal tersebut diatur dalam Pasal 4 RUU EBT yang mengatakan : "Jangka waktu perlindungan kekayaan intelektual Pengetahuan Tradisional dan Ekspresi Budaya Tradisional diberikan selama masih dipelihara oleh Pemilik dan/atau Kustodiannya."
Perlindungan atas folklor sebaiknya diberikan tanpa batas waktu atau abadi. Dengan perlindungan yang abadi maka folklor Indonesia tidak akan mudah dieksploitasi dan diklaim oleh pihak asing. Dengan demikian, dalam undang-undang yang mengatur folklor nantinya, perlindungan atas folklor diberikan tanpa batas waktu atau abadi.

c. Penyelesaian Sengketa

RUU EBT telah mengatur cara penyelesaian sengketa folklor baik melalui pengadilan maupun penyelesaian sengketa di luar pengadilan. Hanya saja, RUU EBT hanya mengatur penyelesaian sengketa dari segi perdata. Adapun ketentuan pidana tidak diatur dalam RUU tersebut. Demikian juga, penyelesaian secara adat juga tidak diatur dalam RUU EBT.

Penegakan hukum terhadap folklor tanpa ada ketentuan pidana dan adat adalah kurang tepat. Adanya sanksi pidana atas pelanggaran folklor tentu dapat memberi efek jera bagi yang melakukan pelanggaran sehingga pelanggaran bisa diminimalisir. Demikian pula, sanksi adat juga seharusnya ditegakkan terhadap pelanggaran folklor jika masyarakat pemilik folklor yang dilanggar memiliki hukum adat yang mengatur hal tersebut. Penyelesaian secara adat dalam beberapa hal dianggap lebih sesuai daripada penyelesaian secara hukum baik secara pidana maupun secara perdata.

Atas dasar hal itu maka sebelum RUU EBT disahkan menjadi UU, RUU tersebut masih harus disempurnakan, terutama mengenai definisi, jangka waktu perlindungan, dan penyelesaian sengketa. Dengan adanya penyempurnaan dalam beberapa hal tersebut maka UU tersebut nantinya akan memberikan perlindungan yang memadai atas folklor. Perlindungan yang memadai atas folklor akan mencegah folklor Indonesia dari eksploitasi yang tidak layak, kepunahan, dan klaim asing.

\section{Simpulan}

Berdasarkan uraian di atas maka dapat disimpulkan bahwa (1). Indonesia mengatur folklor dalam UUHC 2014. Hak cipta atas folklor dipegang oleh Negara. Ada beberapa perubahan perlindungan folklor dalam 
UUHC 2014. Karya yang dilindungi sebagai folklor merupakan salah satu yang berubah. UUHC 2014 mengamanatkan penggunaan folklor harus memperhatikan nilai-nilai yang hidup dalam masyarakat pengembannya. Pengaturan folklor dalam sistem hukum nasional masing-masing negara tidak sama. Ada negara yang mengatur folklor sebagai bagian dari HKI secara umum. Beberapa negara mengaturnya sebagai bagian dari UUHC seperti Indonesia, yaitu antara lain : Australia, Barbados, Iran, Nigeria, Kongo dan Ghana. Beberapa negara mengatur folklor secara sui generis dalam UU yang khusus mengatur folklor seperti Kroasia, Filipina, Vietnam, Azerbaijan, dan Panama; (2). Pengaturan folklor di bawah lingkup undang-undang hak cipta tidak tepat. Pengaturan folklor sebaiknya terpisah dari pengaturan hak cipta. Folklor harus diatur secara tersendiri dalam undang-undang khusus yang mengatur folklor. Indonesia telah membuat RUU Ekspresi Budaya Tradisional (EBT) pada tahun 2007. RUU EBT telah mencakup hal-hal yang sangat mendasar dalam perlindungan folklor. Namun, pengaturan folklor dalam RUU tersebut belum memadai karena masih terdapat beberapa kekurangan yakni definisi dan ruang lingkup folklor kurang luas, perlindungan folklor tidak abadi, dan penyelesaian sengketa yang kurang tepat.

\section{Daftar Pustaka}

Abeyesekere Indunil, "The Protection Of Expressions Of Folklore In Sri Lanka," IIC 2007, 38(2), 183-203, International Review of Intellectual Property and Competition Law, 2007,pp. 183-203.

Antara News.com, "Saatnya Indonesia Melawan Klaim Budaya Oleh Asing," t e r s e d i a d i w e b s i t e http://portal.antaranews.com/print/152 069/saatnya-indonesia-melawanklaim-budaya-oleh-asing, diakses pada tanggal 25 Juli 2011.

Antons Christoph, "What is "Traditional Cultural Expression?", International Definitions And Their Application in Developing Asia", WIPO Journal, 1(1) 2009, pp. 103-116.
Daulay Zainul, 2011, Pengetahuan Tradisional: Konsep, Dasar Hukum, Dan Praktiknya, Jakarta, PT. Raja Grafindo Persada.

Finella Shilta, "Arsitektur Tradisional Di Indonesia", Shilta Finella, "Arsitektur Tradisional Di Indonesia", tersedia di website http://www.scribd .com/doc/53070439/ARSITEKTURT R A D I S I O N A L - IN DONES I A, diakses pada tanggal 10 Oktober 2015.

Fischer Susanna Frederick., "Dick Whittington And Creativity: From Trade To Folklore, From Folklore To Trade", Symposium "The Power of Stories: Intersections of Law, Literature, and Culture The Dick Whittington Story: Its Influences \& Its Impacts, 12 Tex. Wesleyan L. Rev. 5, Texas Wesleyan Law Review, Fall 2005, pp. 566.

Kompas.com, "Mbaru Niang dapat Penghargaan Tertinggi", tersedia di we bsite http://nasiona 1 . kompas.com/read/2012/08/30/0421412 /mbaru.niang.dapat.penghargaan.tertin ggi, diakses pada tanggal 15 Mei 2015.

Kuruk Paul, "Protecting Folklore Under Modern Intellectual Property Regimes: A Reappraisal Of The Tensions Between Individual And Communal Rights In Africa And The United States," 48 Am. U. L. Rev. 769, American University Law Review., April, 1999, pp. 769-849.

Lewinski Silke von, "The Protection Of Folklore", 11 Cardozo J. Int'l \& Comp. L. 747, Cardozo Journal of International and Comparative Law, Summer 2003, pp. 747-768.

Obaldia Irma De, "Western Intellectual Property And Indigenous Cultures: The Case Of The Panamanian Indigenous Intellectual Property Law", 23 B.U. Int'1 L.J. 337, Boston University International Law Journal, Fall 2005, pp. 337-394.

Pemerintah-daerah Provinsi-Nusa-TenggaraTimur, "Mbaru Niang Raih Penghargaan Unesco", tersedia di website http://indonesia. go.id/in/pemerintah-daerah/provinsi- 
nus a - te nggara - t i mur/2162kebudayaan/11488-mbaru-niang-raihpenghargaan-unesco, diakses pada tanggal 17 Mei 2015.

Philips Jake., "Australia's Heritage Protection Act : An Alternative to Copyright in the Struggle to Protect Communal Interests in Authored Works of Folklore", Pacific Rim and Policy Journal, 18 Pac. Rim L. \& Pol'y J. 547, August 2009, pp. 547573.

Prastyo Brian A, "Mencari Format Kebijakan Hukum Yang Sesuai Untuk Perlindungan Folklor di Indonesia", t e r s e di a d i w e b s i t e http://www.lkht.net/index.php, diakses pada tanggal 7 Maret 2011.

Ruesch Meghan., "Creating Culture: Protection Of Traditional Cultural Expressions And Folklore And The Impact On Creation And Innovation In The Marketplace Of Ideas", 35 Syracuse J. Int'1 L. \& Com. 369, Syracuse Journal of International Law and Commerce, Spring 2008, pp. 369-398.

Soekanto Soerjono, 1990, Pengantar Penelitian Hukum, Cetakan Ketiga, Jakarta, UI Press.

Spangler Stephanie, "When Indigenous Communities Go Digital : Protecting Traditional Cultural Expressions Through Integration of IP and Customary Law", 27 Cardozo Arts \& Ent.L.J.709., Cardozo Arts and Entertainment Law Journal, 2010, pp. 709-736.

Sumantri Anton, "Perlu Perlindungan Hukum Bagi Budaya Tradisional Indonesia", tersedia di website http:// www.unpad.ac.id/archives/13603, diakses pada tanggal 15 Mei 2011.

Tempo.news com, "Jepara Fasilitasi Pengajuan Hak Paten", tersedia di w e b s i t e h t t p : / / w w w . tempo.co/read/news/2008/04/02/05812 0239/Jepara-Fasilitasi-Pengajuan-HakPaten, diakses pada tanggal 26 Januari 2014.

Torsen Molly, "Intellectual Property And Traditional Cultural Expressions: A Synopsis Of Current Issues", 3
Intercultural Hum. Rts. L. Rev. 199, Intercultural Human Rights Law Review, 2008, pp. 199-214.

Weeraworawit Weerawit, "Formulating An International Legal Protection For Genetic Resources, Traditional Knowledge And Folklore: Challenges For The Intellectual Propertysystem", 11 Cardozo J. Int'1 \& Comp. L. 769, Cardozo Journal of International and Comparative Law, Summer 2003, pp. 769-783.

Wendland Wend B., "Intellectual Property, Traditional Knowledge And Folklore: Wipo's Exploratory Program", IIC 2002, 33(4), 485-504, International Review of Intellectual Property and Competition Law, 2002, pp. 485-504.

WIPO Intergovernmental Committee on Intellectual Property and Genetic Resources, Traditional Knowledge and Folklore, Glossary Of Key Terms Related To Intellectual Property And Genetic Resources, Traditional Knowledge And Traditional Cultural Expressions, Twenty-Third Session Geneva, February 4 to 8, 2013.

Undang-Undang No. 19 Tahun 2002 tentang Hak Cipta

Undang-Undang No. 28 Tahun 2014 tentang Hak Cipta

"Indonesia Miliki 1.128 Suku Bangsa", tersedia di website http://www.j pnn.com/index.php? $\mathrm{id}=57455 \& \mathrm{mib}=\mathrm{b}$ erita.detail, diakses pada tanggal 26 Januari 2014. 